\title{
Gestão de Projetos de Pesquisa via Web: o caso de uma Instituição de Ensino Superior
}

\author{
Elisa Huzita, Tania Tait, José Luiz Gomes, Maria Dias
}

Universidade Estadual de Maringá

\begin{abstract}
Resumo. Este artigo apresenta o Sistema de Gerenciamento de Projetos de Pesquisa (SGP) que tem por objetivo controlar os projetos de pesquisa $e$ prover informações para tomada de decisão sobre os recursos financeiros e participantes em projetos de pesquisa. Em seu desenvolvimento foram utilizas avançadas técnicas dentro do contexto de software livre e de transparência de informação. Este sistema contribui para apoiar as tomadas de decisão em nível gerencial e também nas atividades em nível administrativo. É possível ter acesso a informações sobre pesquisas desenvolvidas na instituição $e$ contribui para estabelecer parcerias com a indústria e comércio.
\end{abstract}

\section{Introdução}

A gestão de projetos se torna, cada vez mais, importante para a adequada gestão de recursos financeiros nas instituições. A Universidade, apoiada no tripé: ensino, pesquisa e extensão, desenvolve vários projetos cuja gestão é de fundamental importância para o efetivo gerenciamento de recursos humanos, recursos financeiros, acompanhamento dos projetos de pesquisa, acompanhamento das parcerias estabelecidas entre Universidade e Órgãos Públicos e Privados.

Os processos administrativos, dada a suas características, demandam por automatização, o que vem ocorrendo já há algum tempo. No entanto, especificamente no setor público, a automatização dos processos administrativos não tem acompanhado a evolução dos sistemas de informação, marcada ainda por estruturas centralizadas e burocráticas. $\mathrm{O}$ setor de pesquisas não fica alheio a essa situação e sofre os reflexos da falta de informação integrada para gerir os projetos.

Diante deste quadro e da crescente demanda por aplicações Web, fez-se oportuno o desenvolvimento do sistema de gestão de projetos de pesquisa (SGP). Esse sistema insere-se em uma instituição de ensino superior que, atualmente, oferece 49 cursos de graduação, 27 de pós-graduação, abriga cerca de 20.000 alunos e cerca de 1.500 professores/pesquisadores.

Nesta instituição existe um setor específico responsável por gerir os projetos de pesquisa nela desenvolvidos. No entanto, o controle era exercido de forma centralizada e sem a utilização da Web. Isto gerava informações redundantes e, muitas vezes, demora na obtenção de dados estatísticos e de acompanhamento de projetos, importantes para tomada de decisão e divulgação, levando a situações que resultavam em perda de oportunidades para captação de recursos e, também, para o estabelecimento de parcerias. 
Uma característica importante do SGP é a integração com a plataforma Lattes Institucional (pesquisa, produção científica) dentro do contexto de integração de base de dados administrativos (recursos humanos, convênios e controle acadêmico) existentes na Instituição. Assim, minimizou a duplicação de dados constantes nas bases de dados dos diferentes setores, o que acabou trazendo benefícios, como por exemplo, a consistência das informações apresentadas além da extração de informações valiosas contidas na base da plataforma Lattes.

Este artigo tem por objetivo apresentar o SGP. Para tanto se divide nas seguintes seções: metodologia de desenvolvimento do SGP; gerenciamento de projetos; desenvolvimento de sistemas Web; tecnologias usadas; apresentação do sistema e considerações finais.

\section{Metodologia de Desenvolvimento do SGP}

O desenvolvimento do SGP constituiu-se de quatro fases: revisão bibliográfica, escolha do processo de software e das tecnologias, implementação e processo de validação.

A revisão bibliográfica englobou o estudo de gerenciamento de projeto, desenvolvimento para Web, processo de software e tecnologias avançadas de desenvolvimento de software.

Como processo adotou-se o Processo Unificado (Unified Proccess) (JACOBSON et al, 1999). Para a concepção do sistema tomou-se como base a resolução que normatiza os projetos de pesquisa na Instituição e foram realizadas várias reuniões com os stakeholders.

Para a escolha de tecnologias, optou-se pelo uso de software livre, motivado pelos seguintes fatos: por não demandar recursos financeiros, por atender às necessidades do software desenvolvido e por ser uma política que se encontra em implantação pelos órgãos governamentais (estadual e federal).

Ainda, como parte do desenvolvimento, realizou-se a validação do SGP e, em seguida, o treinamento dos usuários.

\section{Gerenciamento de projetos}

Atualmente, o gerenciamento de projetos (GP) atua em duas frentes: aspectos organizacionais e técnicos, notadamente em áreas específicas como a engenharia de software. Desta forma, uma definição que direciona os trabalhos nesta área considera o GP como "a aplicação de conhecimento, habilidades, ferramentas e técnicas às atividades do projeto para atender aos seus requisitos” (PMIa, 2004).

O GP deve ser aplicado formando um sistema que dará suporte à implementação estratégica, uma vez que uma organização é composta de tarefas, pessoas, tecnologia, estrutura e cultura organizacional ((LEAVITT, 1965; KEEN, 1981) apud TAIT, 2000).

A qualidade do GP depende da qualidade do sistema de informações em GP (SIGP) que fornece informações aos stakeholders do projeto utilizando-se de fontes formais e informais, do ciclo de vida do desenvolvimento, que oferece apoio aos Sistemas de Informação (SI) da organização; que facilita a tomada de decisão, que reduz as surpresas ao longo do projeto e está focado nas áreas críticas do projeto. 
O GP é empregado como um processo que leva ao cumprimento das metas, objetivos e missão da organização, trazendo benefícios à organização, aos administradores de topo, aos líderes e membros das equipes de projetos e aos clientes. Dentre os benefícios, podem ser destacados: a melhoria da produtividade, o aumento dos lucros, a maior capacidade e maturidade nas soluções de negócios, maior confiança e previsibilidade da força da organização e maior satisfação no trabalho (BAUER \& KING, 2005).

Para que esses benefícios sejam alcançados, o GP deve ser executado atentando para os fatores que dificultam o gerenciamento, tais como: a cultura organizacional, o surgimento de conflitos, a falta de comunicação e a necessidade de habilidade do gerente de projetos.

\section{Desenvolvimento de Sistemas para WEB}

A disseminação da Internet possibilitou o desenvolvimento de uma nova forma de sistemas de informação - chamada SISWEB. Nesse tipo de aplicação, o fornecimento de informações e de serviços é realizado via Internet, possibilitando maior acesso pela comunidade em geral e necessidade de controle e fornecimento de serviços mais adequados.

Algumas situações merecem destaque no desenvolvimento de sistemas para web como a segurança dos dados; a disponibilidade e o tempo de acesso. Para Pressman (2001), o desenvolvimento de sistemas para web traz a integração entre várias áreas como design, música, marketing, interface humano-computador, entre outras.

Um dos grandes desafios para os sistemas via Web é a segurança dos dados (LAUDON \& LAUDON, 2004) principalmente, devido à vulnerabilidade e uso indevido dos sistemas, cujas ameaças envolvem: falhas de hardware e software; invasões; problemas de telecomunicação; erros humanos etc.

A disponibilidade e o tempo de acesso são cada vez mais exigências dos usuários dos sistemas web devido a crescente utilização e qualificação desses usuários.

O desenvolvimento de sistemas para web necessita estabelecer os elementos que farão parte do sistema, desde a especificação adequada da infra-estrutura de rede e equipamentos que possibilitarão seu uso adequado até a utilização de metodologias de desenvolvimento de software para garantir a qualidade do software.

\section{Tecnologias Usadas}

O SGP foi implementado utilizando a linguagem Java. Esta linguagem foi adotada por ser considerada robusta e possuir características fortes como escalabilidade, portabilidade e segurança, além de ser um padrão aberto e amplamente utilizado.

Como ambiente de desenvolvimento foi escolhido o NetBeans, inicialmente na versão 4.1 e, posteriormente, atualizada para a versão 5.0. Em conseqüência disso, como servidor das páginas JSP foi utilizado o Apache-Tomcat 5.5.9, inicialmente, sendo a versão de produção atual a 5.5.16.

Para a camada de persistência de dados foi utilizado o framework Hibernate (BAUER \& KING, 2005), que tornou transparente o mapeamento objeto-relacional. Outro framework, o Spring (WALLS \& BRENDEIBACH, 2005), é o responsável pelo 
controle das regras de negócio, gerenciando toda a configuração de conexões ao banco de dados, listas de e-mails e servlets.

Como banco de dados, optou-se por manter o IBM DB2 Universal Database, versão 8.2, uma vez que esta é utilizada por outros sistemas na Instituição e desta forma não demandaria um investimento adicional em treinamento e suporte de outro fornecedor.

O SGP conta, também, com uma Ajuda on line, desenvolvida no software HelpNDoc, versão 1.5 - Freeware, e que fica disponível no menu para os usuários autorizados a utilizar o sistema.

O sistema operacional adotado é o SUSE Linux Enterprise, versão 9.

\section{Apresentação do Sistema de Gestão de Projetos - SGP}

\section{O cenário em que se insere o SGP}

A crescente globalização, o rápido avanço tecnológico e o grande volume de informações que precisam ser manuseadas têm demandado por sistemas de informação que ofereçam o apoio necessário aos usuários em uma empresa para a tomada de decisão. Isto não é diferente também em um ambiente universitário/acadêmico.

Assim, este projeto, quando de sua concepção, considerou a necessidade da obtenção ágil de informações consistentes para a tomada de decisões do setor responsável da instituição pela gestão de projetos de pesquisa, em atendimento a outros órgãos governamentais ou dele mesmo nas questões orçamentárias e de produtividade. Era de interesse também tornar disponível, à comunidade geral, informações que permitissem expor o potencial e as contribuições sociais e econômicas que a instituição tem a oferecer.

Além disso, as informações geradas ou solicitadas sobre o coordenador/participantes de um projeto deveriam ser diretamente obtidas da plataforma Lattes Institucional. Ainda, para a sua implementação foram utilizados recursos computacionais, conforme descritos na Seção 5, o que garante portabilidade e escalabilidade de um sistema Web.

\section{Principais usuários}

Este sistema visa atender dois grupos básicos de usuários: o operacional e o gerencial. O grupo operacional é constituído por: professores/pesquisadores da Instituição, a comunidade em geral, os Comitês de Ética, o setor responsável por protocolar todos os documentos que transitam pela instituição, o setor responsável por gerir os convênios decorrentes de execução de projetos de pesquisa.

O grupo gerencial é constituído pela administração superior da Instituição, em particular a Pró-reitoria de Pesquisa e Pós-Graduação.

Os professores/pesquisadores podem assumir diferentes papéis na instituição, que são representados no SGP como: coordenador de projeto, participante de projeto, chefe de departamento e relator para emissão de parecer após análise de projeto.

Em particular, o coordenador de projetos pode ter acesso à janela, ilustrada na figura 1, e iniciar obter informações relativas à forma de sua participação em projetos. Caso tenha atuado apenas como participante ele(a) terá acesso à listagem e caso tenha atuado 
como coordenador poderá selecionar a opção desejada quanto à ação a ser tomada. Todos os projetos são identificados pelo número do processo e título.

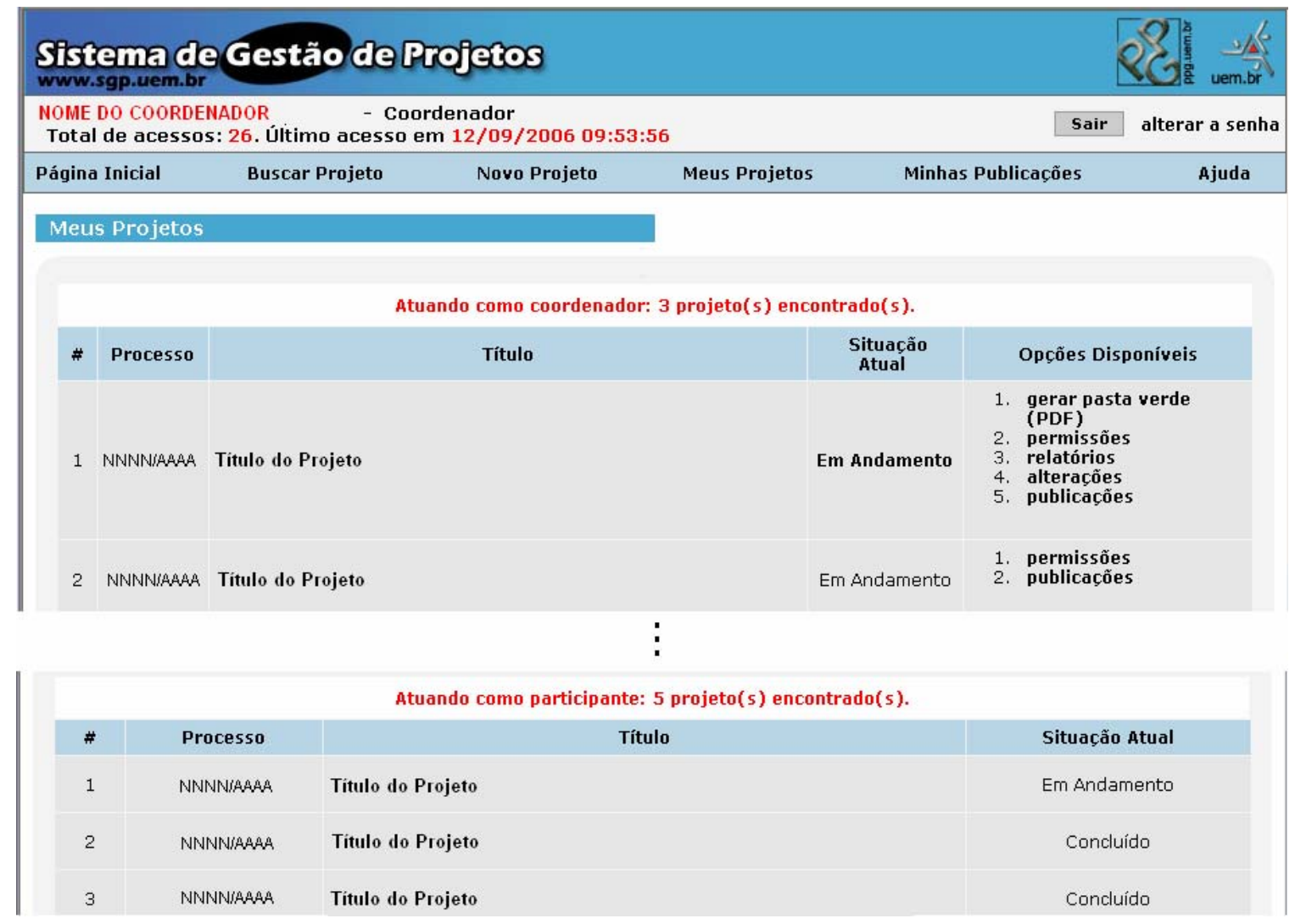

Figura 1 - Informações quanto à forma de atuação, pelo usuário, em projetos.

\section{Principais características funcionais}

No que compete ao coordenador do projeto: pode cadastrar um projeto de pesquisa que deseja desenvolver; acompanhar o trâmite do projeto cadastrado; listar os projetos dos quais é (ou foi) participante (ou coordenador) com as respectivas cargas horárias; vincular a produção de cada um dos projetos na plataforma Lattes.

O coordenador pode, via SGP e sob a supervisão da PPG, solicitar as alterações previstas na resolução que rege os projetos de pesquisa na instituição: inclusão/exclusão de membro de equipe, extensão de prazo, suspensão ou reativação do projeto. Permite ao coordenador enviar os relatórios pertinentes. O coordenador pode, também, vincular ao projeto correspondente as publicações geradas decorrentes da execução do mesmo. É permitida, também, a vinculação do projeto aos programas de pós-graduação quando for o caso. Isto permite um gerenciamento da produção diretamente vinculada aos programas de pós-graduação.

O projeto como um todo foi dividido, para o cadastramento, nas seguintes partes: identificação e possíveis necessidades de análise e deliberação por comitês específicos; objetivos, justificativas, palavras chave; membros da equipe executora; atividades a serem executadas com o período correspondente e a posterior vinculação de atividades 
por participante; preenchimento, se for o caso, de dados de convênio; upload do arquivo no formato $p d f$ com dados detalhados do projeto; assinalamento de permissão quanto à visibilidade pela comunidade a respeito de dados do projeto como por exemplo: objetivos, resultados esperados, equipe executora. Após o envio do projeto ao sistema, é emitida uma notificação de submissão ao coordenador.

O SGP permite o acompanhamento, pelo coordenador, quanto ao trâmite, para saber, por exemplo, em que instância ou setor se encontra o projeto.

No que compete ao chefe de departamento: o departamento no qual o coordenador estiver lotado, será notificado para análise e deliberação do(s) projeto(s) cadastrados(s) no SGP. Neste caso o chefe do departamento receberá a notificação e poderá designar o relator automaticamente pelo sistema. O relator, por sua vez, terá acesso aos dados detalhados do projeto que o apoiarão para elaborar o relato pertinente.

No que compete aos órgãos envolvidos com ética: Os projetos que envolverem pesquisa com seres humanos, animais e organismos geneticamente modificados, deverão ser encaminhados aos comitês responsáveis para análise e deliberação.

No que compete ao órgão envolvido com convênios: O setor da Instituição responsável pelo estabelecimento de convênios, será notificado quanto aos projetos que tiverem firmado convênio para que seja informado o número de convênio correspondente. $\mathrm{O}$ valor do financiamento e o órgão financiador ou do convênio já terão sido informados no ato do cadastramento do projeto.

No que compete à Pró-Reitoria de Pesquisa e Pós-graduação: A PPG é responsável pelo acompanhamento do trâmite de projetos de pesquisa na instituição, no que se refere às alterações dos estados dos projetos e notificação dos órgãos envolvidos. A Figura 2 ilustra a janela que pode ser acessada por este setor para verificar o estado de um determinado projeto. 


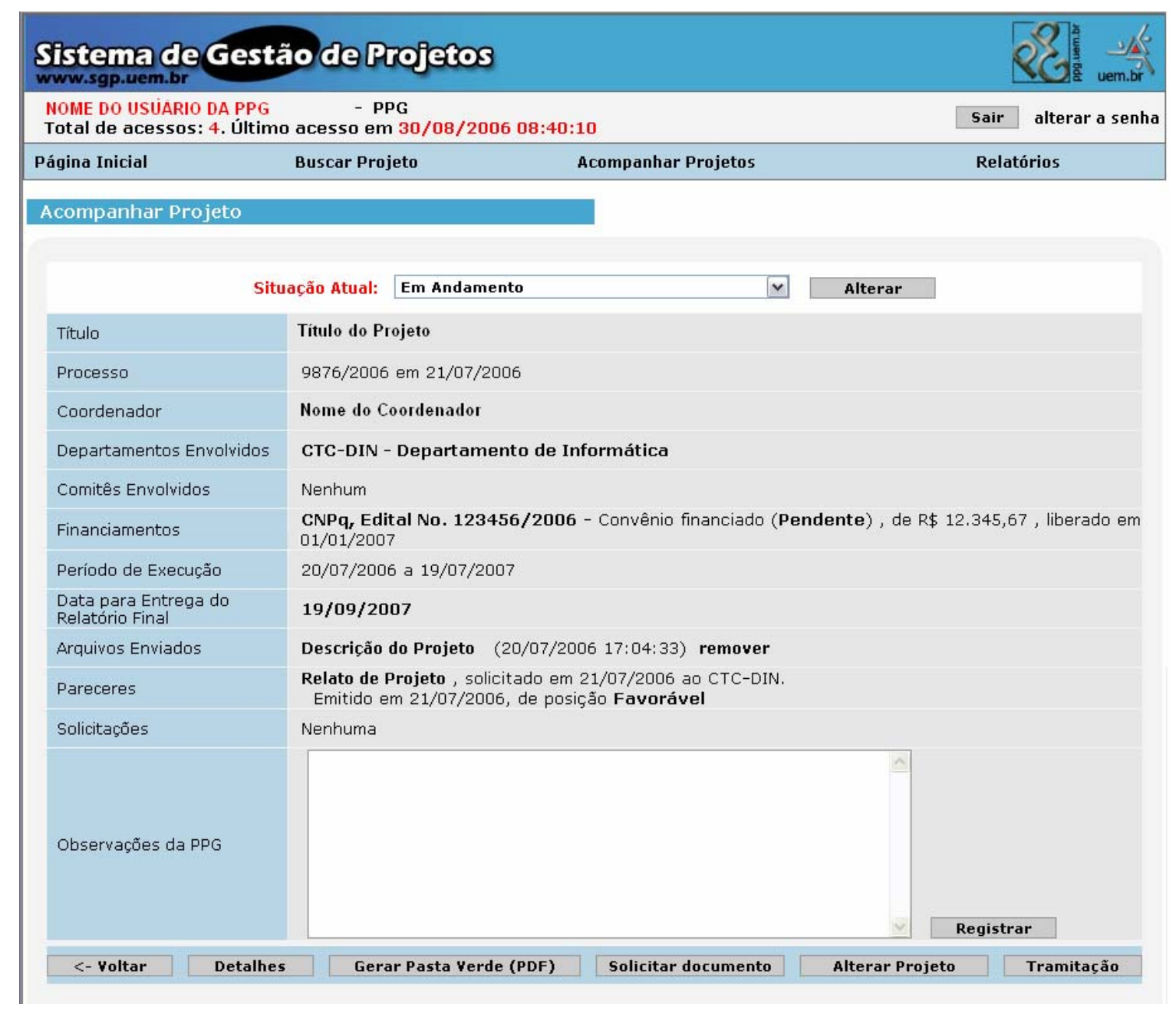

Figura 2: Visualização dos dados do projeto para acompanhamento.

O sistema possibilita ainda, que a PPG envie e-mail aos coordenadores alertando sobre prazos de entrega dos relatórios.

As informações geradas pelo SGP oferecerão à PPG suporte à tomada de decisão.

No que compete ao Protocolo: todo projeto cadastrado será notificado ao protocolo que se encarregará de gerar o número de protocolo que passará a identificar o projeto de pesquisa na Instituição.

\section{Características adicionais:}

Todos os arquivos relativos ao projeto: detalhamento, resolução que delibera sobre o projeto no departamento pertinente e relatórios passarão a fazer parte do corpo dos dados do projeto no banco de dados. O sistema oferece, também, a opção para geração de um arquivo completo, contendo todas as informações.

O SGP permite à comunidade externa visualizar os projetos de pesquisa em execução na Instituição e assim conhecer o potencial da Instituição

Oferece um help on line que auxilia os coordenadores no preenchimento dos detalhes do projeto e os demais usuários da Instituição para ter acesso e utilizar o SGP. 
Para o cadastramento de projeto de pesquisa, por meio do SGP, é necessário que o coordenador e os demais participantes tenham o currículo Lattes Institucional atualizado nos últimos 12 meses. Os participantes externos à instituição deverão possuir o currículo Lattes junto ao CNPq e este fato deverá ser informado no cadastramento do projeto.

\section{Validação}

Várias apresentações foram realizadas para a comunidade universitária visando ao mesmo tempo criar a cultura de utilização do sistema e sanar eventuais problemas.

Um protótipo do SGP foi apresentado para um grupo de representantes de usuários de diferentes áreas de pesquisa e setores da Instituição ligados à pesquisa, os quais teceram considerações para adequação do sistema às suas necessidades e expectativas. Nessa ocasião foi entregue um questionário com perguntas para avaliação do sistema reunidas nos quesitos: facilidade de uso, adequação às necessidades do usuário no tocante à projetos de pesquisa e infra-estrutura disponível/necessária. Para tanto, os usuários acessaram o sistema de seu local de trabalho e/ou residência. Os questionários respondidos foram analisados pela equipe responsável pelo projeto.

\section{Considerações Finais}

O desenvolvimento deste sistema veio atender os anseios da comunidade universitária, em particular, o setor diretamente envolvido na gestão de projetos de pesquisa.

Além da melhoria do processo de tramitação dos projetos de pesquisa obtida com a utilização do SGP, três aspectos devem ser salientados como contribuição advinda tanto do desenvolvimento como do uso do sistema: o uso de tecnologias avançadas, o acesso pela comunidade geral e o significado do SGP para o estabelecimento de políticas de distribuição de recursos para pesquisa na Insituição.

As tecnologias adotadas envolveram o uso de software livre; orientação a objetos; desenvolvimento para Web e uso de framewoks para implementação. Outro aspecto relevante é a integração de várias bases de dados existentes na Instituição.

O uso de software livre e de frameworks de implementação neste sistema servirão como precursores de outros sistemas a serem desenvolvidos, estando já em estudo o desenvolvimento de novos sistemas para atender aos setores responsáveis pela gestão de projetos de extensão e ensino na Instituição.

A comunidade em geral pode, por meio do acesso ao SGP, conhecer os projetos de pesquisa desenvolvidos na Instituição e a aplicação dos recursos públicos. Essa opção foi colocada para garantir a transparência das pesquisas e propicia possíveis contatos para estabelecer convênios com a comunidade, visto que são disponibilizados os dados gerais dos projetos e dos pesquisadores envolvidos. Um aspecto importante é a integração deste sistema com o sistema Lattes permitindo, por exemplo, a vinculação dos resultados alcançados em cada projeto desenvolvido com a respectiva publicação.

O SGP possibilita, através de seus relatórios gerenciais, o conhecimento das pesquisas realizadas; o andamento das mesmas e os recursos captados através dessas pesquisas. $\mathrm{O}$ conhecimento das pesquisas possibilita saber a capacidade da Instituição nas diferentes áreas, bem como as carências para o estabelecimento de estratégias de distribuição de 
recursos internos. Ele facilita, também, a tramitação interna do projeto e o acompanhamento da realização das pesquisas.

O SGP oferece, também, aos gestores informações que apóiam a tomada de decisão sob várias óticas: quantidade de projetos já desenvolvidos e em desenvolvimento, projetos vinculados a cursos de pós-graduação, recursos captados, equipes de projeto de pesquisa existentes na Instituição com a respectiva forma de participação, convênios firmados, entre outros. Tais convênios fortalecem a integração da academia com setores da indústria, comércio e social.

\section{Referencias bibliográficas}

BAUER, C.; KING, G. (2005) Hibernate in action. Manning Publications Co.

CLELAND D. I.; IRELAND L. R. (2002) Gerência de Projetos. 2.ed. Rio de Janeiro: Reichmann \& Affonso Editores. 324 p.

JACOBSON, I.; BOOCH, G.; RUMBAUGH, J. (1999) The Unified Software Development Process, Addison Wesley.

LAUDON, K; LAUDON, J. (2004) Sistemas de Informações Gerenciais administrando a empresa digital. Tradução: Arlete S. Marques. São Paulo: Prentice Hall.

PMIa. (2004) Conjunto de Conhecimentos em GP, 3.ed., Pennsylvania: Project Management Institute Publications, 388 p.

PRESSMAN, R. S.(2001) Software Engineering: A Practtioner's Approach. 5. ed. New York: McGraw-Hill, 860 p.

TAIT, T. F. C. et al. Um Modelo de Arquitetura de Sistemas de Informação para o Setor Público: Estudo em Empresas Estatais Prestadoras de Serviços de Informática. (2000). 263 f. Tese (Doutorado em Engenharia de Produção). Universidade Federal de Santa Catarina, Santa Catarina.

WALLS, C.; BRENDEINBACH, R. (2005) Spring in action. Manning Publications Co. 